\title{
Responsabilidad social empresarial: ¿Por qué? Justificación deontológica de la responsabilidad social empresarial
}

\author{
Susy Caballero Jara \\ M.Sc. en International Development Studies por la University \\ of Amsterdam, Holanda. \\ Administradora por la Universidad del Pacífico, Perú \\ Departamento Académico de Administración de la \\ Universidad del Pacífico, Perú \\ Alonso Villarán Contavalli \\ Ph.D. y M.A. en Filosofía por la Loyola University \\ Chicago,USA \\ Abogado por la Universidad de Lima, Perú \\ Escuela de Postgrado de la Universidad del Pacífico, Perú
}

\section{Resumen}

Mucho se ha discutido en el Perú sobre qué es la responsabilidad social empresarial (RSE) y cómo se implementa. La pregunta de por qué, en cambio, no ha recibido similar interés. Esta es precisamente la interrogante que el presente artículo busca responder: ¿Qué justifica la RSE? ¿Por qué las empresas deben ser socialmente responsables?

Tomando como punto de partida la clasificación en cuatro grandes teorías de responsabilidad social empresarial o corporativa propuesta por Garriga y Melé (2004), a saber, las teorías instrumentales, políticas, integradoras y éticas, se identifican rastros de las mismas en la literatura peruana. De esta forma, se logra un panorama de las distintas justificaciones brindadas por los autores peruanos. Posteriormente, se toma partido a favor de las teorías éticas de RSE, en particular del subgrupo «teoría normativa de los grupos de interés» (stakeholder normative theory), que ve a la RSE como ética aplicada a los negocios, exponiendo sus versiones utilitarista y deontológica, exposición que deja a esta última mejor posicionada. De esta manera, se propone ir más allá de las justificaciones exclusivamente rentistas, según la cual el empresario debe ser socialmente responsable porque le conviene, y considerar la deontología como la justificación del por qué hacer RSE. 


\section{Palabras clave}

Responsabilidad social empresarial, ética, filosofía, deontología, utilitarismo.

\section{Introducción}

El debate sobre la responsabilidad social empresarial o corporativa (RSE) es relativamente nuevo. Se inicia en la segunda mitad del siglo pasado, y comienza a ganar cada vez más protagonismo, expandiéndose desde Estados Unidos y Europa hacia otras partes del mundo. Al Perú llegó en la década de 1990.

Como señalan Benavides y Gastelumendi (2001), es posible identificar ciertos hitos fundacionales de la RSE en el Perú. Entre ellos, la fundación en 1995 de Perú 2021, asociación civil sin fines de lucro cuyo fin es la «difusión y promoción de la Responsabilidad Social (RS) como metodología de gestión empresarial, para que la empresa se convierta en agente de cambio para alcanzar el desarrollo sostenible del Perú» ${ }^{1}$. Otro hito fundacional es la dedicación dada al tema por el grupo SASE desde 1994. En el mundo académico, la Universidad del Pacífico fue una de las instituciones pioneras, sino la primera en investigar el tema. Hoy en día la RSE se ha institucionalizado tanto a nivel empresarial como académico, lo cual se refleja en su inserción en misiones y visiones corporativas, así como seminarios, cursos, conferencias y publicaciones sobre el tema, entre otros.

Como su nombre sugiere, la RSE refiere a la respuesta que, frente a la sociedad, las empresas deben dar por sus acciones e impactos. Se asume, así, que las empresas tienen, siguiendo a Carroll (1991), responsabilidades no sólo económicas - generar riqueza—, sino también legales, éticas y filantrópicas o discrecionales. La RSE, pues, no se refiere a una responsabilidad distinta a las citadas, sino que es un rótulo que abarca a todas ellas.

Estas responsabilidades, sin embargo, no tienen el mismo peso. En efecto, es posible ser sumamente lucrativo violando la ley — por ejemplo, vendiendo narcóticos- o ser lucrativo y respetar la ley en una sociedad en la que ésta se encuentra por debajo de estándares morales mínimos - por ejemplo, que tolere el trabajo infantil. Lo que realmente hace la diferencia entonces, lo que hace que una empresa sea "socialmente responsable», es la dimensión moral, lo que Carroll (1991) denomina responsabilidades éticas —por ejemplo, cobrar precios justos - y filantrópicas o discrecionales - por ejemplo, financiar proyectos culturales. Pero aquí cabe la pregunta que nos ocupa en este artículo, ¿qué justifica las responsabilidades que van más allá de lo económico y legal? A fin de cuentas, el éxito económico es naturalmente deseable y las responsabilidades legales en última instancia son impuestas por el Estado. ¿Por qué, sin embargo, las empresas deben actuar bajo parámetros más exigentes? ¿Qué justifica, en suma, la RSE, en especial a nivel ético?

Esta pregunta demanda una respuesta sólida, especialmente ante los cuestionamientos que, desde el hecho por Friedman (1970), no han cesado.

\section{Objetivo del estudio}

El presente artículo busca responder a la siguiente pregunta: ¿Por qué la RSE? ¿Por qué las empresas deben ser socialmente responsables? En primer lugar, se revisará el estado de la cuestión en el Perú, es decir, se delinearán las principales justificaciones planteadas por la academia local. Seguidamente, se hará una breve pero sustancial crítica a las justificaciones rentistas como criterio determinante para hacer RSE. Finalmente, se realizará un bosquejo comparativo sobre las justificaciones utilitarista y deontológica de la RSE, y se expondrá la propuesta de los autores de optar por esta última.

\section{Marco conceptual}

En la materia de la RSE existen muchas teorías y enfoques, tantos que resulta difícil clasificarlos.

1. http://www.peru2021.org/peru-2021/quienes-somos.html. 
Uno de los pocos esfuerzos en este sentido es el de Garriga y Melé (2004), quienes plantean una división cuatripartita: Teorías instrumentales, políticas, integradoras y éticas.

Brevemente, las teorías instrumentales de la RSE (que en adelante llamaremos rentistas) ${ }^{2}$ ven a la RSE como un mero «medio estratégico para alcanzar objetivos económicos y, en última instancia, crear riqueza» (Garriga y Melé 2004, $53)^{3}$. Las teorías políticas, por su parte, se enfocan en el poder de las corporaciones y el uso responsable del mismo, el cual se materializa en prácticas socialmente responsables. En palabras de los mismos autores, estas teorías «incluyen tanto consideraciones políticas como análisis político en el debate de la RSE» (ibíd. 55). Las teorías integradoras, en cambio, plantean que las empresas «dependen de la sociedad para su existencia, continuidad y crecimiento» (ibíd. 58), lo cual las condiciona o motiva a integrar diversas demandas sociales en su accionar, integración que se materializa en la RSE. Finalmente, las teorías éticas «se enfocan en los requerimientos éticos que cementan la relación entre la empresa y la sociedad» (ibíd. 60). Es decir, justifican la RSE desde la moral. Dentro de éstas últimas, encontramos la teoría normativa de los grupos de interés, que hace referencia a teorías morales occidentales clásicas, como el utilitarismo y la deontología, tratando así a la RSE como ética aplicada a los negocios.

\subsection{Justificaciones rentistas}

Las justificaciones rentistas de la RSE se pueden resumir como sigue: a la empresa le conviene ser socialmente responsable. Estos beneficios se perciben de manera tangible y/o intangible y son la razón por la cual muchas empresas practican la RSE. De ahí la importancia de la medición de resultados, que finalmente será lo que justifique el presupuesto destinado a ese rubro.

Justamente por la búsqueda de beneficios es que se plantea entender el presupuesto de RSE como inversión y no como gasto. Como al respecto dice Solano $(2009,40)$, «lo primero que debe tener en cuenta una empresa o institución es que la RSE no es un gasto sino una inversión, en la medida en que reporta beneficios». Algo similar nos dice Caravedo $(2004,88)$, para quien «la mejora en la calidad de vida de las sociedades es una cuestión de estrategia de las propias empresas».

Entre los beneficios que se obtendrían de dicha inversión, Solano $(2009,40)$ señala la reducción de costos - como resultado de la prevención de conflictos-, el incremento de la productividad y fidelidad de los trabajadores, la mitigación de daños externos y la mejora de la imagen corporativa.

Beneficios similares y otros ya señalaban a principios de siglo Belaúnde, Parodi y Muñoz (2001). Adjuntan a lo ya expuesto que la RSE también fideliza a los clientes, atrae nuevos empleados, mejora la calidad de productos y servicios, y fomenta el buen posicionamiento de la empresa en el mercado.

La fidelización de los clientes mediante la mejora de la imagen corporativa que trae consigo la RSE es también suscrita por Del Castillo y Schwalb (2011).

Otro beneficio vinculado a la RSE, especialmente recurrente en la bibliografía peruana, es el de la ventaja competitiva, siendo defendida por Portocarrero, Tarazona y Camacho (2006), Marquina (2010), Vives y Peinado-Vara (2011) y Del Castillo y Schwalb (2011). En palabras de estos últimos autores, y citando a Porter, «las empresas deben integrar una perspectiva social en sus procesos para comprender a la competencia y orientar las estrategias de responsabilidad social hacia la estrategia del negocio y, así, convertirse en una fuente importante de innovación y ventaja competitiva» (Del Castillo y Schwalb 2011, 6). Sobre el mismo tema, Marquina $(2010,72)$ nos dice que «la responsabilidad social es entendida como un factor de competitividad, lo que

2. Creemos que son mal llamadas instrumentales pues hay teorías que, no siendo rentistas, son también instrumentales, empezando por el utilitarismo, que como veremos también puede ayudar a fundar la RSE. Es decir, las teorías rentistas y utilitaristas son subgrupos que conforman, junto con otras, las teorías instrumentales. Por ello, sería incorrecto igualar los términos «rentistas» e «instrumentales», cuando claramente el segundo es más amplio.

3. Las traducciones del inglés al español que prosiguen fueron realizadas por los autores de este artículo. 
implica involucrarse en temas como los derechos humanos, las prácticas laborales, las prácticas operacionales justas, la comunidad y su desarrollo y el de la relación con sus consumidores».

La RSE también abriría nuevos mercados para las empresas que la adoptan, concretamente mercados más sofisticados como los de los países llamados "desarrollados», en donde hay una cultura de responsabilidad social más consolidada y cuyos ciudadanos están dispuestos a pagar más por bienes que cumplan estos estándares. Así lo señalan Del Castillo y Schwalb $(2011,7)$ :

En el caso de los países latinoamericanos, el ICR [Índice de Competitividad Responsable] demuestra que practicar la RSE constituye una oportunidad para ingresar en la economía global y capturar clientes más exigentes con mayor rentabilidad.

Un beneficio adicional que se derivaría de hacer RSE es mencionado por Eckhardt, Gironda, Lugo, Oyola y Uzcátegui $(2009,17)$, quienes, además de referir lo relativo a la imagen corporativa, y específicamente refiriéndose a las empresas mineras, dicen que la RSE mejora el flujo de inversiones:

De esta manera las empresas logran involucrarse en las dinámicas del desarrollo local con el fin de mejorar su imagen internacional y a la vez el flujo de inversiones en proyectos mineros (para las empresas cuyas acciones se cotizan en bolsa es mucho más importante aún).

Las justificaciones rentistas también son recurrentes entre los empresarios. Es así que, en un estudio que busca analizar las motivaciones, creencias y percepciones de directivos empresariales peruanos sobre la RSE, Del Castillo, en Kogan $(2012,165)$, concluye:

Según lo observado, los directivos que gestionan la RSE en las más grandes empresas del Perú son altamente sensibles al estímulo externo y gestionan la RSE en respuesta a la identificación de riesgos. En efecto, en las más grandes empresas del Perú, el espíritu de trascendencia de la empresa a través de un rol activo como ciudadana corporativa es aún limitado, dejando el mayor protagonismo a las motivaciones económicas o legales y a la lógica del poder como marco para gestionar las relaciones con los otros actores.

Ahora bien, el hecho que las justificaciones rentistas sean las más citadas no significa que los mismos autores no reconozcan otras justificaciones (como se verá más adelante), sino que denotaría la importancia de esta visión pragmática para el público objetivo al que se dirigen. Por su formación, los empresarios y gerentes tienden a enfocarse en los resultados de la empresa. Por ello, una visión pragmática que aporte a estos resultados es fundamental para que se tome la decisión de hacer una u otra cosa. Digamos que la justificación rentista viene a ser el «argumento de venta» o «marketing» de la RSE. En ese sentido, Caravedo $\left(2000^{a}, 25\right)$ nos dice:

Pero, ¿qué se requiere para incorporar y expandir una filosofía y un compromiso de responsabilidad social en las empresas, los cuales contribuyan a una redefinición estratégica general? Desde nuestra perspectiva se requieren las siguientes condiciones: Que el empresariado esté convencido de que la inversión social que adopta la empresa le genera beneficios, algunos habitualmente intangibles, pero existentes; y que esos beneficios incrementen los beneficios generales de la empresa.

\subsection{Más allá de las justificaciones rentistas}

La defensa de la RSE no se limita, como se ha adelantado, a justificaciones rentistas. Hay otro tipo de consideraciones que suman a la causa de la RSE, a saber, las propias de las teorías integradoras, políticas y éticas de las que nos hablan Garriga y Melé (2004).

\section{Las teorías integradoras}

Las teorías integradoras de la RSE se «enfocan en la integración y satisfacción de las demandas sociales» (Garriga y Melé 2004, 63), en la medida que las empresas dependen de la sociedad para su existencia y continuidad. La conocida frase de Makower «no hay empresas sanas en sociedades enfermas», a la que Caravedo (2004) hace referencia, grafica este enfoque. Esta visión 
ciertamente es instrumental, pues ve a la RSE como un medio necesario para la subsistencia de la empresa, pero se diferencia de la rentista pues la motivación no es el lucro sino la supervivencia.

En línea con esta posición, Schwalb y García (2003, 82) nos dicen que «las prácticas socialmente responsables son cada vez más comunes, ya que nuestros empresarios están empezando a darse cuenta de la imperiosa necesidad de desarrollarlas, y de que estas prácticas constituyen un requisito para su subsistencia». De forma similar, Belaúnde et. al. $(2001,6)$ declaran que «las empresas están comprendiendo que su rol no es solamente generar y repartir utilidades en el corto plazo, sino también atender las necesidades de su entorno, con el propósito de garantizar su propia estabilidad y permanencia en el mercado». Asimismo Durand, en Sanborn y Portocarrero $(2008,240)$, señala que «se habla de un nuevo clima de competitividad global donde la corporación podrá sobrevivir si y solo si se involucra económica y socialmente».

Entre las teorías integrativas encontramos una de especial influencia en el Perú: la gerencia de los grupos de interés (stakeholder management). Como explican Garriga y Melé (2004, 59), esta teoría «está orientada hacia los stakeholders o personas que afectan o son afectadas por las políticas y prácticas corporativas». Esta aproximación también es recogida por Schwalb y Malca $(2004,104)$ :

Cuando hablamos de la dirección o manejo de los grupos de interés nos referimos al proceso que emprenden los directivos de las empresas para evitar que sus objetivos choquen con los objetivos y expectativas de los distintos grupos de interés.

Uno de los beneficios producto de una adecuada alineación de las relaciones de los grupos de interés con la estrategia de la empresa, señalan Del Castillo y Schwalb $(2011,21)$, es la «obtención y conservación de la licencia social para operar. Un compromiso efectivo de la empresa con los grupos de interés contribuye a crear una visión común que más adelante puede desarrollar una agenda compartida y fortalecer la licencia para operar». En términos similares, Durand, también en Sanborn y Portocarrero (2008, 236), afirma que la RSE es una respuesta ante las presiones sociales para lograr la licencia social o, como le llama, legitimidad frente a la sociedad.

La falta de licencia social para operar ha traído muchas consecuencias negativas, especialmente en el sector extractivo, el cual registra el mayor número de problemas socio-ambientales ${ }^{4}$. La conciencia respecto a la necesidad de contar con ella ha crecido ya que para la empresa puede significar la paralización de sus operaciones y para la industria un mayor desgaste de su reputación y la propagación de conflictos en otras zonas. En el caso concreto de las empresas mineras, Eckhardt et. al. $(2009,17)$ destacan la práctica de RSE en respuesta a la deficiente normativa que dificulta la obtención de la licencia social:

La necesidad de manejar estos escenarios para obtener la llamada «licencia social» ha conducido a las empresas mineras hacia la adopción voluntaria de instrumentos internacionales de responsabilidad social empresarial dentro de sus gestiones, de forma articulada con las operaciones $y$ de manera voluntaria, pues la legislación peruana a pesar de los esfuerzos realizados durante los últimos dos años no está a tono con los avances normativos internacionales en la materia, especialmente en temas como la participación ciudadana en los estudios de impacto ambiental (EIA) y la fiscalización en general. De esta manera las empresas logran involucrarse en las dinámicas del desarrollo local con el fin [...] de resolver los conflictos que puedan amenazar en el corto, mediano o largo plazo la viabilidad de sus operaciones y futuras inversiones.

\section{Las teorías políticas}

Pasando a las teorías políticas, éstas ven a la RSE como una forma responsable de gestionar el poder que las empresas, especialmente las multinacionales, tienen hoy en día. Estas teorías

4. Así lo demuestra el Reporte de conflictos sociales elaborado por la Defensoría del Pueblo en noviembre de 2012. 
no son muy influyentes en la literatura peruana pero aun así están presentes.

Que las grandes empresas son hoy en día agentes políticos es un hecho. Basta con notar que los presupuestos que manejan muchas de ellas son, individualmente, mayores que los presupuestos de más de un Estado o lo suficientemente grandes como para tener poder significativo en muchas economías. En Estados Unidos, por ejemplo, los activos de cinco bancos (JPMorgan Chase, Bank of America, Citigroup, Wells Fargo y Goldman Sachs), que equivalen a $\$ 8.5$ trillones, representaron el $56 \%$ de su economía a fines del año $2011^{5}$. Esto sin lugar a dudas les da un poder inmenso, lo cual puede poner en peligro la democracia. En algunos casos, incluso, llega a reemplazar al Estado en sus funciones. A esto se refiere Caravedo, en Vives y PeinadoVara $(2011,35)$, cuando nos dice que «muchas empresas han asumido funciones del gobierno en el campo social. De esta manera, las empresas se han convertido en actores políticos y no sólo económicos y ambientales». Sobre lo mismo, Schwalb y Malca $(2004,8)$ nos advierten que «las empresas poseen mucho poder, el cual debería encontrarse acompañado de igual cantidad de responsabilidad».

Una de las teorías políticas más difundidas de RSE, como explican Garriga y Melé $(2004,56)$, es la del ciudadano corporativo (corporate citizenship). En sus propias palabras,

A pesar que la idea de la firma como ciudadano no es nueva [...] recientemente ha aparecido entre los profesionales un renovado interés en este concepto, debido a ciertos factores que han tenido un impacto en la relación entre los negocios y la sociedad. Entre estos factores, especialmente dignos de notarse es la crisis del Estado de Bienestar y el fenómeno de globalización. Estos, junto con el proceso de desregularización y decrecimiento de costos con las mejoras tecnológicas, ha significado que algunas grandes compañías multinacionales tengan mayor poder económico y social que algunos gobiernos. El marco de la ciudadanía corporativa intenta dar una explicación [looks to give an account] a esta nueva realidad [...].

En el Perú, esta teoría ha sido acogida por autores como Schwalb y Malca $(2004,13)$, quienes atribuyen a la empresa deberes y derechos similares a los de cualquier ciudadano:

La responsabilidad social empresarial no es más que la extensión de la responsabilidad individual que tiene todo ciudadano hacia su entorno físico social, esto es lo que se ha venido a llamar "ciudadanía corporativa». El concepto de ciudadanía corporativa implica que la empresa, al igual que el ciudadano, tiene deberes y derechos para con la sociedad y los debe cumplir y respetar.

\section{Las teorías éticas}

Finalmente, con relación a las teorías éticas de la RSE, éstas «se enfocan en lo que es [moralmente] correcto para alcanzar una buena sociedad» (Garriga y Melé, 2004, 64). Los fundamentos éticos con los que intentan fundar la RSE varían de acuerdo al autor. En la literatura peruana encontramos los siguientes ejemplos.

En primer lugar encontramos a Solano $(2009,43)$, quien hace referencia principalmente a la ética como respeto absoluto al otro, señalando que la RSE y la ética van de la mano:

Un alto compromiso implica una alta dosis de ética en la acción empresarial. No hay RSE sin ética, por más que hagamos inversiones millonarias. Pero, ¿qué es ética? María Elena Galindo (2003) la define como: «el desarrollo propio, sin atentar contra el libre desenvolvimiento de los demás», es decir, es algo meramente subjetivo. De esta definición se desprende que el comportamiento ético en una empresa implica no sólo evitar y combatir la corrupción, como se concibe normalmente, sino respetar a los demás en todo lo que compete a sus libertades, anhelos y potencialidades.

5. http://Www.businessweek.com/articles/2012-04-19/big-banks-now-even-too-bigger-to-fail. 
Schwalb $(2010,18)$, por su parte, presenta a la RSE como una nueva ética que prioriza al ser humano:

Podría entonces afirmarse que el recorrido conceptual enfocado inicialmente en los aspectos del macroentorno de la gestión empresarial ha dado un viraje importante para desplazarse hacia una perspectiva más "micro», que busca recuperar la importancia del ser humano como centro y razón de ser. Repensar las definiciones actuales de desarrollo a partir de una mirada de interculturalidad, incorporar al «otro» $y$ reconocer en ello la perspectiva ciudadana, son exigencias que se anteponen a cualquier pretensión de los que consideramos como socialmente responsable. En este sentido, la RSE constituiría un llamado a una ética nueva y la búsqueda de un continuo equilibrio de los tres ejes principales de generación de valor: ambiental, social $y$, por supuesto, económico.

Del Castillo y Schwalb $(2011,6)$ resaltan la obligación moral de las empresas con la sociedad como una motivación importante de la propagación de la RSE a nivel mundial:

En efecto, en la actualidad la incorporación de la RSE en la gestión empresarial se ha convertido en un tema de interés mundial. Su adopción ha sido principalmente motivada por la creciente conciencia de que esta es una obligación moral de las empresas para contribuir a la sostenibilidad social y ambiental.

Finalmente, Caravedo, en Vives y PeinadoVara $(2011,42)$, habla de la RSE como una ética de la coherencia en la que sostiene que la empresa debería mantener una misma línea de comportamiento y actitud al relacionarse con los distintos grupos de interés:

La responsabilidad social de la empresa es una ética de la coherencia. Las empresas desarrollan múltiples actividades en diferentes ámbitos y dimensiones. Por ejemplo, si se mira hacia dentro de la empresa se puede ver que hay políticas y prácticas laborales, que el clima de la empresa impacta sobre todos sus trabajadores influyendo en su nivel de satisfacción como seres humanos, en su rendimiento como trabajadores, en la calidad de los productos a partir de los procesos utilizados para su elaboración. Si se mira hacia fuera de la empresa, se podrá ver que genera expectativas de demanda de empleo o crea situaciones sociales, culturales y ambientales antes inexistentes en la comunidad en la que tiene presencia. Dependiendo de la comprensión que la alta dirección de la empresa tenga sobre su capacidad de impacto y las responsabilidades que debiera asumir por ello, desarrollará políticas y prácticas en algunos o en todos esos campos.

Dentro de las teorías éticas, Garriga y Melé (2004, 64) mencionan la llamada teoría normativa de los grupos de interés o stakeholder normative theory (que no debe confundirse con el stakeholder management). Esta escuela, explican los mismos autores, «requiere referencia a alguna teoría moral (kantiana, utilitarismo, teorías de justicia, etc.)».

En la bibliografía peruana se encuentran pocos rastros de la teoría normativa de los grupos de interés. Los primeros en plantear esta vía son Schwalb y García $(2003,36)$, quienes ya a principios de siglo mencionaban la referencia a la filosofía moral como una manera de justificar la RSE:

Son útiles tres criterios filosóficos, los cuales configuran las bases filosóficas de la responsabilidad social empresarial.

- El utilitarismo en la toma de decisiones pretende lograr el más grande bienestar para el mayor número de personas.

- Los derechos individuales responden a la protección de la dignidad humana ${ }^{6}$.

- La justicia pretende asegurar una igual distribución de obligaciones y beneficios.

6. Referencia indirecta a la deontología kantiana, en nuestra opinión. 
Otro autor que hace uso de las grandes escuelas morales para justificar la RSE es Marquina (2008, 28), quien en un artículo sobre RSE y ética nos dice que «los negocios [...] deben ser desarrollados bajo el imperativo moral de hacer lo correcto. Una empresa puede ser considerada ética o no, de acuerdo con la perspectiva con la que sea analizada: la teleológica o la deontológica».

Pereyra $(2009 b, 102)$ es otro autor que vincula la filosofía moral y los negocios, concretamente con referencia al utilitarismo y la deontología: «La gestión y en particular el proceso de toma de decisiones debe volverse a asumir como estándares de evaluación los principios de la ética deontológica y alejarse así de la corriente utilitarista o egoísta que se sustenta en el fin por encima de los medios».

Hablando directamente de la RSE, el mismo Pereyra (2009a) cambia de punto de referencia, y nos remite a la ética de la virtud de Aristóteles, algo que Garriga y Melé (2004), correcta o incorrectamente, ubican en una subcategoría distinta a la que nos ocupa ahora, a saber, la del bien común (the common good), según la cual el fin de la empresa no es el lucro, sino precisamente el bien común.

\section{Metodología}

Para la elaboración del presente artículo se utilizaron métodos cualitativos como estudio pensamiento lógico-analítico y pensamiento crítico.

\section{Análisis}

\subsection{Límites de la justificación rentista}

Si bien es válido y hasta positivo reconocer las ventajas que trae consigo la RSE, es inadecuado justificarla con argumentos exclusivamente rentistas. El problema no es reconocer los beneficios que trae consigo la RSE, sino el reducir su justificación a éstos, algo no común entre autores peruanos quienes como hemos visto tienden a sumar justificaciones de diverso tipo, aunque sí en autores extranjeros, incluso notables como Kotler y Lee (2004).
Como con respecto a la ética en general dice MacKinnon (2009, 36): «¿No asume [el egoísmo ético] que cualquier cosa es totalmente correcta siempre que sirva al mejor interés del individuo? Torturar seres humanos o animales será permitido siempre que sirva los intereses de uno. Cuando no sean de uso a los intereses personales, las virtudes tradicionales de la honestidad, fidelidad y lealtad no tendrán valor». Extendiendo esto al ámbito de la RSE, si el principio de la conveniencia es lo que la justifica, es decir, lo que le da validez moral, la empresa hará lo que ésta conlleva siempre que le resulte conveniente y todo lo contrario cuando no.

Cuando se dice que a la empresa le conviene ser socialmente responsable y que por ello debe adoptar prácticas de este tipo, estamos colocando a la mera conveniencia por encima de la RSE (y de la moral en general). El hecho es que, como la experiencia personal enseña, no siempre conviene hacer lo correcto. Muchas veces es todo lo contrario: hacer lo correcto nos trae problemas. Si hacer lo correcto estuviese tan en armonía con lo que nos es conveniente, no sería tan difícil ser una buena persona. ¿Qué se hará, entonces, en tales circunstancias, en situaciones en las que hacer lo moralmente correcto, promover la RSE, ponga en juego el futuro del negocio? $\mathrm{Si}$ el principio supremo de la moralidad es la mera conveniencia, no habrá duda: abandonar la RSE.

Al subordinar la RSE a la conveniencia, en definitiva, se deja abierta la puerta a que el día en que a la empresa no le convenga ser socialmente responsable -lo cual con suerte será algo excepcional- haga exactamente lo contrario a lo que la RSE dispone. En otras palabras, se estará sembrando en la empresa la semilla del oportunismo, además de edificar a la institución de la RSE sobre arena movediza.

Otro problema vinculado con la justificación rentista se revela al considerar el rol que tienen las intenciones en la moralidad. Kant, cuya ética se delinea abajo, dice que las intenciones son cruciales para determinar la bondad de toda acción. No basta, pues, con hacer lo correcto, sino que hay que hacer lo correcto porque es lo correcto, sin importar sus consecuencias. Adoptar la RSE con la intención de reducir costos, mejorar 
la imagen corporativa, fidelizar clientes, etc. vicia el acto. El acto será conforme a lo que ordena la moralidad, pero no propiamente moral.

Las razones mencionadas llevan a concluir que es necesario ir más allá de las justificaciones rentistas de la RSE. No necesariamente abandonarlas, pero poner el énfasis en otro tipo de justificaciones $y$, en caso de conflicto, dar la última palabra a las justificaciones éticas por las razones que siguen.

\subsection{Justificaciones desde la filosofía moral}

Como se mencionó, para fundar la RSE sobre cimientos sólidos se debe ir más allá de las razones rentistas, y en opinión de los autores optar por la llamada teoría normativa de los grupos de interés. Más concretamente, pretendemos mostrar la solidez que brinda el recurrir a la filosofía moral en busca de verdaderas justificaciones de la RSE. No por nada se trata de teorías consolidadas, que han pasado con creces la prueba del tiempo. Dada la limitación del espacio, el enfoque se hará en las dos grandes escuelas morales nacidas en la modernidad y que tienen gran influencia en la actualidad: el utilitarismo y la deontología.

Como se ha visto, Marquina y Pereyra recurren a las mismas. El problema es que, al hacerlo, cometen imprecisiones que ameritan ser aclaradas.

El problema con Marquina $(2008,28)$ es que equipara la teleología con el consecuencialismo (del cual el utilitarismo es subespecie), algo ciertamente discutible sino errado de plano. En el caso de la deontología, por su parte, le da tintes consecuencialistas: "Una empresa podrá ser ética si se orienta hacia metas y objetivos que beneficien no solamente a su organización, sino también a su comunidad vinculada y a la sociedad en su conjunto, siempre que al hacerlo se respeten los valores morales dicha sociedad". Al respecto, como veremos, para la deontología las acciones son buenas o malas en sí mismas, no en función a sus consecuencias.

En el caso de Pereyra, el problema es que iguala el utilitarismo con el egoísmo, cuando el utilitarismo en realidad es una doctrina más cercana al altruismo (sin llegar a ser altruismo puro, pues al final lo que importa es la felicidad neta). Su apuesta por la deontología coincide con la posición de los autores, pero no en esto último, que Mill mismo niega expresamente en su obra, como se explicará abajo.

A continuación, se expondrán el utilitarismo y la deontología y cómo ayudarían a justificar la RSE.

\section{a. El utilitarismo}

El utilitarismo es un consecuencialismo, es decir, una teoría moral que propone que la bondad de las acciones la determinan sus consecuencias. En el caso del utilitarismo, el bien a producir es la felicidad, y más particularmente la felicidad entendida como placer. Esto es así, en opinión de los filósofos ingleses y padres de la doctrina Bentham (1748-1832) y Mill (1806-1873), porque el placer es lo único bueno en sí, es decir, lo único que es deseado en sí mismo y no como medio para algo más. En palabras de Mill $(2007,7)$,

El credo que acepta como fundamento de la moral la Utilidad, o el Principio de la mayor Felicidad, mantiene que las acciones son correctas en la medida en que tienden a promover la felicidad, incorrectas en cuanto tienden a producir lo contrario a la felicidad. Por felicidad se entiende placer y la ausencia de dolor; por infelicidad, dolor y la privación de placer.

Dicho en otras palabras, el primer principio de la ética para el utilitarismo ordena promover la mayor cantidad de felicidad entre la mayor cantidad de gente.

Al medir la bondad de las acciones en función a sus consecuencias, el utilitarismo demanda un análisis costo beneficio que incluya al menos lo siguiente: los otros seres humanos; el monto neto, la intensidad y la duración del placer; así como la fecundidad y la probabilidad de la acción. A estos elementos cuantitativos propuestos por Bentham (1988), Mill añade la distinción cualitativa ya que hay placeres cualitativamente mejores que otros: nadie cambiaría una vida humana miserable por la de un cerdo feliz.

En su obra el Utilitarismo, y luego de delinear la doctrina, Mill pasa a defenderla de potenciales críticas. Entre ellas, es fundamental resaltar la que acusa al utilitarismo de ser un egoísmo, un malentendido muy extendido hasta el día de hoy, 
como hemos visto. Frente a esto, Mill recuerda que el utilitarismo demanda considerar la felicidad de todos los afectados y no sólo del agente. Por ello, habrá situaciones que uno deberá sacrificar su propia felicidad para promover la felicidad de la mayoría. El utilitarismo, en definitiva, no es un egoísmo.

Desde la perspectiva del utilitarismo, la RSE no es buena en sí misma, sino instrumentalmente: se justificará siempre y cuando se demuestre empíricamente lo que parece de sentido común, esto es que promueve la mayor cantidad de felicidad entre la mayor cantidad de gente. El argumento a grandes rasgos sería así:

Premisa 1: Es un deber promover la mayor cantidad de felicidad entre la mayor cantidad de gente.

Premisa 2: La RSE promueve la mayor cantidad de felicidad entre la mayor cantidad de gente.

Conclusión: Es un deber promover la RSE.

Demostrar la premisa 2 no es tarea sencilla. Es cierto que en principio la RSE parece promover la felicidad general, en la medida que la RSE es un llamado al empresario a considerar a todos los afectados al momento de tomar una decisión, procurar el bienestar de los stakeholders y el de la propia empresa. Pero esta no es toda la historia.

Para entender su complejidad basta notar lo siguiente: la premisa implícitamente dice que la RSE siempre promueve la mayor cantidad de felicidad entre la mayor cantidad de gente, algo que la experiencia empírica sin duda rebate, aunque sea de manera excepcional. E incluso si no lo hiciera, es algo indemostrable de manera categórica, por la misma razón que hace imposible empíricamente probar que el sol «saldrá» mañana por el horizonte ${ }^{7}$. Si más bien decimos que la RSE generalmente promueve la mayor cantidad de felicidad entre la mayor cantidad de gente, surge otro problema, a saber, que estaremos frente a un principio moral secundario, que admite excepciones. Es posible, en efecto, pensar en instancias más excepcionales en que prácticas que van en contra de la RSE promoverán la mayor cantidad de felicidad entre la mayor cantidad de gente. De esto se sigue que el utilitarismo, en el mejor de los casos, recomendará la RSE pero no la ordenará de manera categórica. Lo único categórico en esta doctrina es la promoción de la felicidad.

\section{b. La deontología}

Al hablar de ética deontológica es ineludible hablar de Kant (1724-1804), fundador de su versión moderna.

Para Kant, a diferencia de Mill, el principio de felicidad no puede fundar la ética al menos por dos razones: su naturaleza relativa y el ser fuente de heteronomía. Por felicidad Kant entiende la satisfacción de nuestras inclinaciones y necesidades, las que, en su opinión, varían de persona en persona e incluso en la misma persona con el transcurrir del tiempo. Guiarnos por ella, en consecuencia, equivaldría a navegar con un compás roto. Peor aún, cuando se actúa en pos de la felicidad se hace condicionado por el objeto de nuestro deseo, heterónoma y no autónomamente.

El primer principio de la ética no reside, pues, en la facultad de desear sino en la razón. A este principio Kant llama ley moral o imperativo categórico. Es categórico pues ordena incondicionalmente, a diferencia de los imperativos hipotéticos que siguen la forma si quieres $\mathrm{x}$, entonces haz $\mathrm{y}$.

Muy bien, pero ¿qué ordena el imperativo categórico? En la Fundamentación para una Metafísica de las Costumbres, Kant (2002) frasea la ley moral de al menos tres maneras distintas:

- Fórmula de la ley universal: «Obra sólo según aquella máxima por la cual puedas querer que al mismo tiempo se convierta en una ley universal» (Ak. IV, 421).

- Fórmula del fin en sí mismo: «Obra de tal modo que uses a la humanidad, tanto en tu persona como en la persona de cualquier otro, siempre al mismo tiempo como fin $y$ nunca simplemente como medio» (Ak. IV, 429).

7. Esto mismo reta a las justificaciones rentistas: los beneficios que prometen deben ser probados. 
- Fórmula del reino de los fines: «El ser racional tiene que considerarse siempre como legislador en un reino de los fines posible merced a la libertad de la voluntad, ya sea como miembro, ya sea como jefe» (Ak. IV, 434).

Es importante reiterar que estas tres formulaciones no son tres leyes distintas sino la misma fraseada de manera diferente.

Por lo dicho, se sigue que si el principio de felicidad y la ley moral colisionan, debe prevalecer el segundo. Dicho de otra forma, ser bueno es más importante que ser feliz.

Pero no basta -añade Kant respecto a un punto sobre el que ya hemos dicho algo- con hacer lo que la ley moral ordena (mera «legalidad» moral), sino que la intención es crucial: la acción no sólo debe ser hecha en conformidad con la ley moral sino por ella. Robar es malo en sí mismo, ser generoso es bueno en sí mismo. Ni su bondad ni su maldad es definida por sus consecuencias, como defienden Bentham y Mill, sino incondicionalmente por la ley moral.

Desde la perspectiva deontológica, la RSE se justificaría de demostrarse que las prácticas que defiende pasan la prueba o se derivan del imperativo categórico. El argumento iría como sigue:

Premisa 1: Es un deber tratar a los demás y a uno mismo como fin y no meramente como medio (segunda formulación del imperativo categórico).

Premisa 2: La RSE conlleva tratar a los demás y a uno mismo como fin y no meramente como medio.

Conclusión: Es un deber promover la RSE.

Comoenelcaso del principioutilitarista, demostrar o probar la premisa 1 es tarea del filósofo puro. La premisa 2, por su parte, y a diferencia de la premisa 2 del argumento utilitarista, es menos compleja de probar. Para ello, basta notar que la RSE, como hemos visto, nos ordena respetar a todos los afectados por las actividades de la empresa, es decir, a los trabajadores, clientes, accionistas y miembros de la comunidad en donde opera. La RSE se vuelve utilitarista cuando al llamado a respetar a los stakeholders se le añade el estribillo «puesto que de esta forma se promueve la mayor cantidad de felicidad entre la mayor cantidad de gente». Pero en Kant queda así como estaba: debemos respetar a los stakeholders porque respetarlos es bueno en sí mismo, sin importar las consecuencias. Dicho de otra manera, respetar a los stakeholders equivale a tratarlos como fines y no meramente como medios (lo cual para Kant incluye promover su felicidad), lo cual es un deber incondicional.

Quizá el mayor reto de la RSE desde la deontología kantiana se presenta cuando recordamos el rol que Kant le da a las intenciones morales, algo que hemos revisado al criticar las teorías rentistas. Los empresarios, nos diría el sabio de Königsberg, que promueven la RSE por razones rentistas no serán propiamente morales. Es, en todo caso, un problema que yace del lado del empresario interesado, y no en Kant y su doctrina moral.

\section{Conclusión}

¿Por qué, pues, las empresas deben adoptar la RSE? Las respuestas dadas por cada una de las teorías revisadas son las siguientes:

- Teorías «instrumentales» (aquí rebautizadas como rentistas): Porque a las empresas les conviene.

- Teorías integrativas: Porque las empresas dependen de la sociedad para su subsistencia.

- Teorías políticas: Porque las empresas, especialmente las multinacionales, son actores políticos poderosos, lo cual trae consigo responsabilidades.

- Teorías éticas: Porque la moral lo ordena (sea desde el utilitarismo, la deontología, etc.).

\} Teorías normativas de los grupos de interés:

V Utilitarismo: Porque la RSE promueve la mayor cantidad de felicidad entre la mayor cantidad de gente.

V Deontología: Porque la RSE implica tratar a los demás y a uno mismo como fin y no meramente como medio.

Las teorías rentistas como justificación exclusiva de la RSE fallan, entre otras cosas, porque 
colocan al principio de la conveniencia como primer principio de la ética. Esto puede llevar a traicionar la RSE en ciertas circunstancias, como por ejemplo en tiempos de crisis económica. Además, por el rol que tienen las intenciones en la moralidad. Se puede recurrir a ellas en la medida que suman razones, siempre y cuando no sea el criterio último o exclusivo para justificarla.

Por ello se propone ir más allá del rentismo, y dentro de las teorías no rentistas inclinarse por las teorías éticas, y más concretamente, por la teoría normativa de los grupos de interés, la que recurre a las grandes escuelas morales clásicas, dado su peso histórico, influencia y, sobre todo, solidez argumentativa. Entre estas, se eligió al utilitarismo y la deontología por ser dos de las más influyentes teorías morales de nuestros tiempos. La RSE, así vista, no sería más que un nuevo fruto de aquél árbol ancestral que es la filosofía moral.

En el cuadro 1, se muestra un resumen de las cuatro teorías y sus argumentos sobre por qué hacer RSE.

Cuadro 1

Justificaciones de la responsabilidad social empresarial

\begin{tabular}{|c|c|c|}
\hline Teorías & Justificación & Frases representativas \\
\hline $\begin{array}{l}\text { Instrumentales } \\
\text { (rentista) }\end{array}$ & Conveniencia & $\begin{array}{l}\text { - La RSE reduce costos, mejora la imagen, incrementa la fidelidad y productividad de } \\
\text { los trabajadores, es fuente de ventaja competitiva, atrae inversionistas, etc. }\end{array}$ \\
\hline Integrativas & Subsistencia & $\begin{array}{l}\text { - Hacer RSE garantiza la esabilidad y permanencia de la empresa en el mercado y } \\
\text { facilita la licencia social para operar en sectores sensibles como el minero. }\end{array}$ \\
\hline Políticas & $\begin{array}{l}\text { Obligación } \\
\text { política }\end{array}$ & $\begin{array}{l}\text { - El poder de las empresas viene acompañado de responsabilidad, la que se } \\
\text { concreta en la RSE. }\end{array}$ \\
\hline Éticas & $\begin{array}{l}\text { Obligación } \\
\text { moral }\end{array}$ & - Hacer RSE es un deber moral d las empresas. \\
\hline -Utilitarismo & Promover & - La RSE promueve la mayor cantidad de felicidad entre la mayor cantidad de gente. \\
\hline -Deontología & $\begin{array}{l}\text { Tratar a las } \\
\text { personas como } \\
\text { fin y no como } \\
\text { medio }\end{array}$ & -Respetar a los stakeholders (es decir, hacer RSE) es bueno en sí mismo. \\
\hline
\end{tabular}

Ciertamente, el utilitarismo y la deontología son doctrinas rivales. Las dos, pues, no pueden estar en lo cierto: una de ellas necesariamente está más cerca de la verdad. Dados a elegir, creemos que la deontología prevalece, entre otras cosas, pues para el utilitarismo la RSE es condicionalmente buena - buena en la medida que promueva la felicidad general- lo cual no necesariamente siempre ocurrirá. Para la deontología kantiana, en cambio, la RSE aparece como buena en sí misma, como hemos explicado.
Es posible, vale recalcar, explorar otras corrientes morales más contemporáneas como, por mencionar algunas, la ética de Levinas (2005), de cada vez mayor influencia en el mundo de la ética, - la peruana y neokantiana desarrollada por Miró Quesada (2003). Sin embargo, algo creemos haber logrado: superar las teorías rentistas como justificación última o exclusiva de la RSE y trazar un camino en pos de una justificación definitiva de la misma, la que, creemos, debe seguir la estela de Kant. 


\section{BIBLIOGRAFÍA}

ARISTÓTELES

2010 Ética a Nicómaco. Madrid: Gredos. Trad. Julio Palli.

BELAÚNDE, L., L. Parodi, y M. Muñoz

2001 Cómo promover la responsabilidad social empresarial en el Perú: Marco legal e institucional. Lima, Perú: Universidad del Pacífico, Centro de Investigación.

BENAVIDES, B., y G. Gastelumendi

2001 Responsabilidad social empresarial: Un compromiso necesario. Lima, Perú: Universidad del Pacífico, Centro de Investigación.

BENTHAM, J.

1988 The principles of morals and legislation. Buffalo, N.Y: Prometheus Books.

\section{BLOOMBERG BUSINESS WEEK}

2012 "Big Banks: Now Even Too Bigger to Fail" (versión electrónica). Extraído de: http://www. businessweek.com/articles/2012-04-19/bigbanks-now-even-too-bigger-to-fail. Consulta: 15 de octubre de 2012.

CANESSA G. y E. García

2005 El ABC de la Responsabilidad Social Empresarial en el Perú y en el Mundo. Lima, Perú: Perú 2021.

\section{CARAVEDO, B}

2010 ¿Es posible innovar el sentido común? Lima, Perú: Universidad del Pacífico, Centro de Investigación.

2004 La revolución de las significaciones: Liderazgo, empresa y transformación social. Lima, Perú: Universidad del Pacífico, Centro de Investigación.

2000a Empresa, Responsabilidad Social y lucha contra la pobreza. Lima, Perú: Universidad del Pacífico, Centro de Investigación.

2000b Responsabilidad social: una nueva forma de gerencia. Lima, Perú: Universidad del Pacífico, Centro de Investigación.

1999 Lo social y la empresa a fines de siglo: Responsabilidad social empresarial: avances y logros. Lima, Perú: Universidad del Pacífico, Centro de Investigación.

1998a Perú, empresas responsables. Lima: SASE, Servicios para el Desarrollo. 1998b La Responsabilidad Social de las Empresas Privadas en el Perú. SASE y Perú 2021.

CARROLL, A.

1991 «The pyramid of corporate social responsibility: Toward the moral management of organizational stakeholders». Business Horizons, 34, 4, pp. 39-48.

DEFENSORÍA DEL PUEBLO

2012 Reporte de conflictos sociales N 103 (versión electrónica). Extraído de: http://www. defensoria.gob.pe/conflictos-sociales/home. php. Consulta: 10 de diciembre de 2012.

DEL CASTILLO, E., y M. Schwalb

2011 Guía práctica para la gestión de proyectos con responsabilidad social. Lima, Perú: Universidad del Pacífico, Centro de Investigación.

ECKHARDT, K., A. Gironda, J. Lugo, W. Oyola y R. Uzcátegui

2009 Empresas mineras y población: Estrategias de comunicación y relacionamiento. Lima: Universidad ESAN.

FRIEDMAN, M.

1970 "The social responsibility of business is to increase its profits». New York Times, 13 setiembre de 1970.

GARRIGA, E. y D Melé

2004 «Corporate Social Responsibility Theories: Mapping the Territory». Journal of Business Ethics, 53, 2, pp. 51-71.

KANT, I.

2009 Crítica de la razón práctica y Crítica del juicio. Madrid: Editorial Gredos.

2002 Fundamentación para una metafísica de las costumbres. Madrid: Alianza Editorial. Trad. Roberto R. Aramayo.

KOGAN, L. (Ed.)

2012 La caja negra. Lima, Perú: Universidad del Pacífico, Centro de Investigación.

KOTLER, P., y N. Lee

2005 Corporate Social Responsibility. Doing the Most Good for Your Company and Your Cause. NJ: John Wiley \& Sons.

LEVINAS, E.

2005 Totality and Infinity. Pittsburgh, PA: Duquense University Press.

MACKINNON, B.

2009 Ethics: Theory and contemporary issues. Belmont, CA: Wadsworth/Cengage Learning. 
MARQUINA, P.

2010 «Competitividad responsable y el desarrollo inclusivo del Perú». Revista Strategia, año 5 (número 16), pp. 71-75.

2008 «Ética, negocios y responsabilidad social». Revista Strategia, año 2 (número 7), pp. 28-31.

MILL, J.

2007 El utilitarismo. Madrid: Alianza Editorial.

MIRÓ QUESADA C., F.

2003 Ser Humano, Naturaleza, Historia. México: Paidós.

PEREYRA, J.

2009a «Responsabilidad Social empresarial ¿Una moda más?». Revista Strategia, año 4 (número 12), pp. 102-105.

2009b «El divorcio entre la gestión y la ética». Revista Strategia, año 4 (número 13),101-102.

PERÚ 2021

2012 Quiénes Somos (versión electrónica). Extraído de: http://www.peru2021.org/principal/ categoria/quienes-somos/16/c-16. Consulta: 10 de diciembre de 2012.

PORTOCARRERO, F.

2000 Empresas, fundaciones y medios: La responsabilidad social en el Perú. Lima, Perú: Universidad del Pacifico, Centro de Investigación.

PORTOCARRERO, F. y C. Sanborn.

2003 De la caridad a la solidaridad: Filantropía y voluntariado en el Perú. Lima, Perú: Universidad del Pacífico, Centro de Investigación.

PORTOCARRERO, F., B. Tarazona y L. Camacho

2006 Situación de la responsabilidad social empresarial en la micro, pequeña y mediana empresa en el Perú. Lima, Perú: Universidad del Pacífico, Centro de Investigación.

SANBORN, C. y S. Portocarrero (Eds.)

2008 Filantropía y cambio social en América Latina. Lima, Perú: Universidad del Pacífico, Centro de Investigación.

SCHWALB, M.

2004 Beneficios de la responsabilidad social empresarial y las inversiones socialmente responsables. Lima, Perú: Universidad del Pacífico, Centro de Investigación.
2010 Experiencias exitosas de responsabilidad social empresarial. Lima, Perú: Universidad del Pacífico, Centro de Investigación.

SCHWALB, M y E. García

2003 Evolución delcompromisosocial delasempresas: Historia y enfoques. Lima, Perú: Universidad del Pacífico, Centro de Investigación.

SCHWALB, M., y O. Malca

2004 Responsabilidad social: Fundamentos para la competitividad empresarial y el desarrollo sostenible. Lima, Perú: Universidad del Pacífico, Centro de Investigación.

SCHWALB, M., C. Ortega y E. García

2003 Casos de responsabilidad social. Lima, Perú: Universidad del Pacífico, Centro de Investigación.

SOLANO, C.

2009 Responsabilidad social: Estrategias sostenibles para el desarrollo y la competitividad. Lima, Perú: ESAN Ediciones.

VIVES, A., y E. Peinado-Vara (Eds.)

2011 La Responsabilidad Social de la Empresa en América Latina. Washington: Banco Interamericano de Desarrollo. 